\title{
ADAPTING MANUFACTURING TO CUSTOMER BEHAVIOR
}

Lessons learned from trading goods on public market places

Stephan Kassel, Kay Grebenstein

University of Applied Sciences, Dr.-Friedrichs-Ring 2a, 08056 Zwickau, Germany,Email: Stephan.Kassel@fh-zwickau.de

Abstract: The globalization of competition urges manufacturers to reduce costs and simultaneously provide a better service to the customer. To achieve both goals, the prediction of customer behaviour plays a key role. This can be done by observation of the customers on public market places like eBay. These observations have to be combined with events influencing customer preferences. For this purpose, a decision support system for retailers was designed, combining an expert system with a data warehouse. The experiences of this project can be utilized for manufacturing companies as well.

Key words: event-driven customer behaviour, demand prognosis, knowledge management, data warehouse, public markets, decision support, customer-driven manufacturing

\section{INTRODUCTION}

Due to globalization and the emergence of customer-oriented markets the companies have to change their behaviour and provide additional value to their customers. This can be done in different ways, e.g. by providing a better service or by individualizing products to the customer. Customeroriented or agile manufacturing (Kidd 1994, BüyüKözkan 2004) are the key words of this latter means of achieving customer satisfaction. But this leads to great problems for the manufacturing industry. With a higher degree of customer-orientation it becomes more and more impossible to produce goods in advance, leading to the advent of supply chain management (An and Fromm 2005, Becker 2005). This has been true for parts of the

Please use the following format when citing this chapter:

Kassel, Stephan, Grebenstein, Kay, 2006, in International Federation for Information Processing (IFIP), Volume 207, Knowledge Enterprise: Intelligent Strategies In Product Design, Manufacturing, and Management, eds. K. Wang, Kovacs G., Wozny M., Fang M., (Boston: Springer), pp. 127-133. 
manufacturing industry, the special purpose machines industry, but it becomes more and more reality for consumer goods industry, too. For example, in the high-price car industry, the customers can choose from dozens of colours and a multitude of features. Even in the convenience goods industry, the number of products is ever growing.

On the other hand, there is the need to reduce stock capacities to achieve a minimized capital binding in products on stock. This can partially be solved by introducing lean production concepts (Womack and Jones 1996; Liker 2004). But often it leads to a dilemma, which is actually solved on the backs of the customers, who have to wait for high-price products very long, and/or on the back of the employees, who always have to stand by to solve customer needs quickly when they arise.

Some of the problems seem to be not solvable, because a multitude of manufacturing processes need time to be done. So every means to prognosticate the point of time, when the customer will buy some special goods, is increasingly important and can become a competitive advantage for the manufacturing companies.

There are two different ways to identify customer behavior successfully. One way to meet with general acceptance is to introduce customer relationship management (CRM). This approach tries to identify the needs and wishes of the individual customers to manage customer relationship and to provide a feedback channel to increase customer satisfaction (Kamakura et al. 2005). The second way is to analyze changes of demand on public market places and identify potential reasons for these changes (Liu et al. 2000). This is a generic approach and uses statistical procedures for the examination of the observed behavior. In the analysis of the reasons for the changes of customer behavior, one can identify different causes, as done by Verhoef et al. (2002). There are common and long-term trends, which are influenced by technological progress, fashions and culturally changing habits of the customers. Another class of reasons consists of special events, which can be periodic (like onset of winter, beginning of summer, Christmas or other holidays, or even week-ends or paydays), or acyclic (like Olympics, world championships, or big pop music events). This analysis and the utilization of the identified correlations is the core of our research activities. 


\section{A SELF-ADAPTING DECISION SUPPORT SYSTEM FOR TRADING ON PUBLIC MARKET PLACES}

\subsection{The initial research objective}

Sales channels have changed dramatically in the past decade. After the ecommerce hype leading to big retailers selling via individually built ecommerce systems, public market places were built to provide a tool for selling goods for everyone. This trend will continue for the next years, as forecasted by „Jupiter Research" (Salcedo 2004): "The online commerce market in Europe will grow from $€ 29$ billion in 2003 to $€ 117$ billion in 2009 , with 61 percent of European Internet users buying online and spending an average of $€ 843$ per buyer. Increased online tenure, growth in the online population, and improved broadband uptake will be the main drivers behind this solid growth". The same trend can be seen in each region of the world. Especially eBay was a big success story, starting with a platform to enable people everywhere selling things they didn't need any longer. But not only private trade was enhanced by eBay. Power sellers started up their businesses on this public market place and were successfully selling goods via this channel. Lately, the huge customer base of eBay attracted big retailers to make use of this trading channel, too.

To make business on these public market places, one doesn't need any complex e-commerce system. There are solution providers which deliver out-of-the box functionality for connecting inventory management systems with the market place. This can be done by using web services, a very flexible and light-weighted connection method for information systems.

So the connection to the public market place as a sales channel is neither a problem nor rather expensive. But for new participants on this market, there are a number of open issues which have to be solved to make optimal use of the sales channel. When should one place goods on the market? How many goods should be placed? How long should the goods be placed, or which auction duration is optimal? Which is the right (starting) price for the placed goods? Which sales campaign (fixed price and/or auction) should be chosen? The right answer to these questions depends on the goals of the seller, which can be a mixture of optimizing the selling volume or optimizing the sales price or both.

In the next sections, a solution for these issues is outlined, which has been prototypically implemented by the authors as part of an industryfunded research project. 


\subsection{Solution overview}

The industrial partner AGETO has built a software system which interfaces between mail order systems and different market places like eBay. The product data from the sellers are transformed to offers and placed on the public market automatically; the orders on the market place are routed to the seller systems for fulfillment.

To be successful on the public market place, one has to learn from the participants which are already prospering. So the first step consisted of utilizing the knowledge of diverse power sellers. The knowledge of the power sellers should be shared by explicitly including it in a common knowledge base, as proposed by Sol (2002). An expert system was built, which determines the amount of goods to be placed on the market place as well as the exact point in time for the placement. The rules of the expert system reflect experience knowledge of power sellers. As an important influencing factor for the placement of offers on the market, facts and rules on external incidents like special events were included in the knowledge base from the beginning. The expert system was built using the open source shell Mandarax (Dietrich 2004)

In the next step, the actual sales data were collected and prepared to be utilized. A data warehouse has been built to hold internal data of the market place as well as external data of different data bases delivering information on events which were supposed to be influential for the sales success. This data warehouse, which has been built as a PostgreSQL database, was the first step towards business intelligence, enabling the enterprise to set up a successful customer relationship solution including the analysis of cross selling opportunities, as described by Vitt (2002). Basically, the development of prices over time, auction length, placement time, and external factors like seasons, weather, holidays, were included in the data base. From the basic data, classification numbers were derived to provide compact information on sales success from different perspectives. These classification numbers were related to the external events to determine possible correlations between the external events and the internal sales data.

After building the data warehouse and performing initial correlation analysis, the expert system and the data warehouse had been coupled to provide a closed loop application. This allowed for the automatic adjustment of the expert system rules to the feedback of the classification numbers leading to a higher conformance of the expert system with the changing behavior of the customers. Thus, recurring trends could be computed and used for a better prognosis of market activities. 


\subsection{Lessons learned from building the knowledge-based decision support system}

In the project, a prototypical implementation of a knowledge based decision support system has been built. We have created an expert system containing a set of rules depicting the knowledge of power sellers for placing auctions and fixed-price bids on public market places. This expert system was coupled with the AGETO eBay web service system to provide sellers with assistance in placing their offers on the public market. This part of the work could be achieved well by using a public domain expert system shell.

The planning and implementation of the data warehouse has been challenging, caused by the vast amount of data we had from the user behavior on the market place. We needed to transform numerous log files to provide us with the data needed to measure the success factors of a bid. In extension, the external data, like weather forecasts, had to be condensed and classified. This classification was not easy, and has to be adjusted depending on the correlation quality which can be achieved with the classification.

The analysis of the data warehouse for finding correlations between external events and sales figures has been done manually. Classification numbers have been built and were used together with the external event data as input for some statistical measures. The found correlations were promising, but further analyses have to be done to find other connections as well. Maybe, we have to use data mining for raising the quality of the analysis.

Connecting the data warehouse with the expert system could be done easily; the expert system has a data base connection and could be enhanced to use some of the classification numbers as facts, leading to new results.

\section{TRANSFERRING THE IDEAS TO MANUFACTURING}

The principles of the presented solution can be utilized for a better prognosis of customer demand. The observation of special markets and the analysis on sales figures on these markets can be combined with external events influencing customer behaviour. A feedback system can be developed to predict demand for the manufactured good more precisely. Useful for this observation are especially the open public marketplaces, where you can achieve a multitude of data concerning preferences of customers. Additionally, the sales channel of public markets is rather fast. You can identify trends from the beginning, because the goods are rapidly traded, and the prices of auctions are market driven. This advantage of public market 
places is already utilized by big online retailers leveraging this sales channel as an ideal test market for new products, which are not announced with expensive marketing campaigns. This can be done anonymously, so the retailers get immediate response on customer affectations.

This advantage could be used by the manufacturers as well; they could sell prototypes via this channel and get immediate customer feedback.

By further enhancing the system with a direct connection to the production planning system, a demand driven manufacturing could be established, which is depending on the predicted customer demand. Together with the more direct interaction with the customers by using public markets, this behaviour can bear advantages in some industries, because the trade margin can be transformed to customer service and lower prices, further enhancing customer satisfaction and retention.

\section{REFERENCES}

1. An, C., Fromm, H., eds., (2005), Supply Chain Management on Demand, Springer, Berlin.

2. Becker, T., (2005), Prozesse in Produktion und Supply Chain optimieren, Springer, Berlin.

3. BüyüKözkan, G., Derelİ, T., and Baykasoğlu, A., (2004), A survey on the methods and tools of concurrent new product development and agile manufacturing, J. Int. Manuf. 15(6): 731-751.

4. Dietrich, J., (2004), A Rule-Based System for eCommerce Applications, in: Proceedings of Knowledge-Based Intelligent Information and Engineering Systems: 8th International Conference, Springer LNCS 3213 / 2004, Heidelberg, 455-463.

5. Kamakura, W., Mela, C.F., Ansari, A., Bodapati, A., Fader, P., Iyengar, R., Naik, P., Neslin, S., Sun, B., Verhoef, P.C., Wedel, M., and Wilcox, R., (2005), Choice Models and Customer Relationship Management, Marketing Letters 16(3-4): 279-291.

6. Kidd, P.T., (1994), Agile Manufacturing, Addison-Wesley, Reading.

7. Liker, J., (2004), The Toyota Way, McGraw-Hill, New York, New York.

8. Liu, B., Hsu, W., Han, H.-S., and Xia, Y., (2000), Mining Changes for Real-Life Applications, in: Data Warehousing and Knowledge Discovery: Second International Conference, DaWaK 2000, London, UK, September 2000. Proceedings, Y. Kambayashi, M. Mohania, A M. Tjoa, eds., LNCS 1874-2000, 337-346.

9. Salcedo, L., (2004), Market Forecast Report European Commerce, 2003-2009, JupiterResearch, Jupitermedia Corp. 
10. Sol, H., (2002), Expert Systems and Artificial Inteligence in Decision Support Systems, Kluwer Academic Publishers.

11. Verhoef, P.C., Franses, P.H., and Donkers, B., (2002), Changing Perceptions and Changing Behavior in Customer Relationships, Marketing Letters 13(2): 121-134.

12. Vitt, E., (2002), Business Intelligence: Making Better Decisions Faster, Microsoft Corporation, Redmond

13. Womack, J.P., and Jones, D.T., (1996), Lean Thinking, Simon \& Schuster, New York, New York. 